\title{
THEEFFECTIVENESSOFGINGER COMPRESS ON NON-SPECIFIC LOW BACK PAIN
}

\author{
H. W. Lem* and A. C. Lee \\ Faculty of Sports Science and Coaching, Universiti Pendidikan Sultan Idris, Tg Malim, Perak, \\ Malaysia
}

Published online: 10 November 2017

\begin{abstract}
The purpose of this study was to identify the effectiveness of ginger compress in relief non-specific low back pain and reduce functional disability due to low back pain. After screening, 15 participants were randomly allocated into two groups: experimental group $(n=8)$ received ginger compress treatment for 20 minutes per session, three sessions per week for a total of ten sessions and control group $(n=7)$ did not received any treatment. Numeric Rating Scale for pain and OswetryDisability Questionnaire were used to measure pain and functional disability before and after the intervention. This study revealed the experimental group indicated significantly pain relief $(p=0.000)$ and disability reduced $(p=0.000)$ after three weeks intervention. This study concludesthat ginger compress is effective in pain relief and reduces functional disability in patients with non-specific low back pain.
\end{abstract}

Keywords: ginger compress, non-specific low back pain, Oswetry Disability Questionnaire

Author Correspondence, e-mail: lemfighting@gmail.com

doi: http://dx.doi.org/10.4314/jfas.v9i6s.87 


\section{INTRODUCTION}

Low back pain (LBP) is a disorder in modern society that affects in an acute,recurrent or chronic manner with $80 \%$ of the population suffering from it at least once in their life [1].Low back pain is usually classified as 'specific' or 'non-specific'. A specific LBP refers to a diagnosis resulting from a trauma, injury, infection or structural pathology, whereas non-specific LBP indicates no known structural problem causing the pain [2]. Specific causes account for less than $20 \%$ of cases of back pain so-called "red flags" which symptoms and signs that point to a specific cause [3]. In up to $85 \%$ of all cases of low back pain, the mechanism of pain is poorly understood and is classified as non-specific due to unknown origin [4]. Due to the great impact on life quality of individualssuffering from non-specific low back pain, low back pain (LBP) is still an emergingtopic in scientific as well as in popular discussions.

Low back pain results in significant levels of disability and restrictions on usual activity, such as the inability to work [5]. Studies in the United Kingdom identified back pain as the most common cause of disability in young adults [6].Usually, LBP and disability are influenced by physicalactivities and posture, but the etiological factors associatedwith LBP are difficult to identify. The goal of patients with LBP is pain free and restoration offunctionas quickly and safely as possible [7].

Ginger has been widely used as a spice toenhance the flavour of food and beverage. It has been used as an anti-inflammatory and anti-rheumatic for musculoskeletal disorders in Ayurvedic and Chinese medicine for more than 2500 years [8,9]. Ginger(Scientific name: Zingiberofficinale) belongs to the family of Zingiberaceae has been widely used traditionally for a variety of medicinal purposes, one of which is for the treatment of pain [10].Ginger compress are used to manage arthritis symptoms in Chinese folk medicine [11] and European hospitals specializing in complementary health care [12]. A ginger compress is a macrobiotic remedy placed on the skin to stimulate blood flow, thereby warming the area and relieving pain. A ginger compress is applied by soaking a towel in hot ginger water and placing it on the skin for 20 minutes. Although many studies had shown that ginger is effective as a natural pain reliever and an anti-inflammatory agent in rheumatoid arthritis and osteoarthritis 
$[13,14,15]$, limited research has been conducted on ginger applied externally especially for the low back pain.

Thermotherapy is the therapeutic application of heat. Moist heat is preferable to dry heat, because moist heat will penetrate deeper into the tissues. Moist heat can be obtained by using a hot wet towel, hot water bottle or heated gel pack over it. Heat is most commonly used for its immediate soothing and palliative effects. Heat has been used as a therapeutic modality for many years and has been shown to increasecirculation, increase metabolism, decrease tissue stiffness, decrease painand relax muscle spasms [16,17].Some reviews recommend superficial heat application for pain relief $[18,19]$. However, the evidence to support the utilization of superficial heat for low back pain is limited.

The purpose of this study is to identify the effectiveness of ginger compress in relief non-specific low back pain and reduce functional disability due to low back pain. The finding of this study may help to support the effectiveness of ginger compress as a form of moist heat in relief low back pain and reduce functional disability due to low back pain. Besides, the finding of this study may help introduce a new moist heat therapy treatment for non-specific low back pain individual as one of the suitable intervention to relief pain and to reduce functional disability.

\section{METHODS}

An experimental design was used to investigate the effect of ginger compress on individual with non-specific low back pain. The sampling method used was the purposely random sampling. Participants in this study were students from UniversitiPendidikanSultan Idris with at least 18 years old and had complaint of low back pain for at least one month. Non-specific Low back pain are characterized by the absence of signs of a serious underlying conditions such as cancer, infection, or cauda equina syndrome through self-report screening questionnaire and pain $\geq 5$ on a Numeric Rating Scale for pain. Individuals were excluded if they had one or more of the following conditions such as skin disease, inflammation or infection on back, a history of back fracture or back surgery, spinal stenosis or radiculopathy, fibromyalgia, fever, body mass index $>30$, hemi or paraparesis, infectious diseases (such as 
Tuberculosis or AIDS), malignant tumours, metal implants in the low back region, impaired sensation at the lower back region, hyper or hypo-sensitive to heat, open wounds at back and circulatory problems. Patients who were having regular treatment with clinic or hospital during the study period were excluded as well.

After the screening process, there were 15 eligible participants have been recruited and randomly assigned into Experimental Group $(n=8)$ and Control Group $(n=7)$. The randomization method used was simple randomization with stratification. Stratification factors were gender. The study was conducted for three weeks. Before the three weeks ginger compress intervention and after intervention, all the participants were required to have an assessment regarding degree of pain by using Numeric Rating Scale (NRS) for pain and functional disability due to low back pain by using Oswestry Low Back Pain Disability Questionnaire. The experimental group were having ginger compress as their treatment intervention for 20 minutes a day for three weeks with a total of ten intervention sessions while the control group did not received any treatment. The data collected from this study was analysed by using independent sample t-testin Statistical Package for Social Science (SPSS) version 20. The level of significance was determined prior to the study at $\rho=0.05$. 


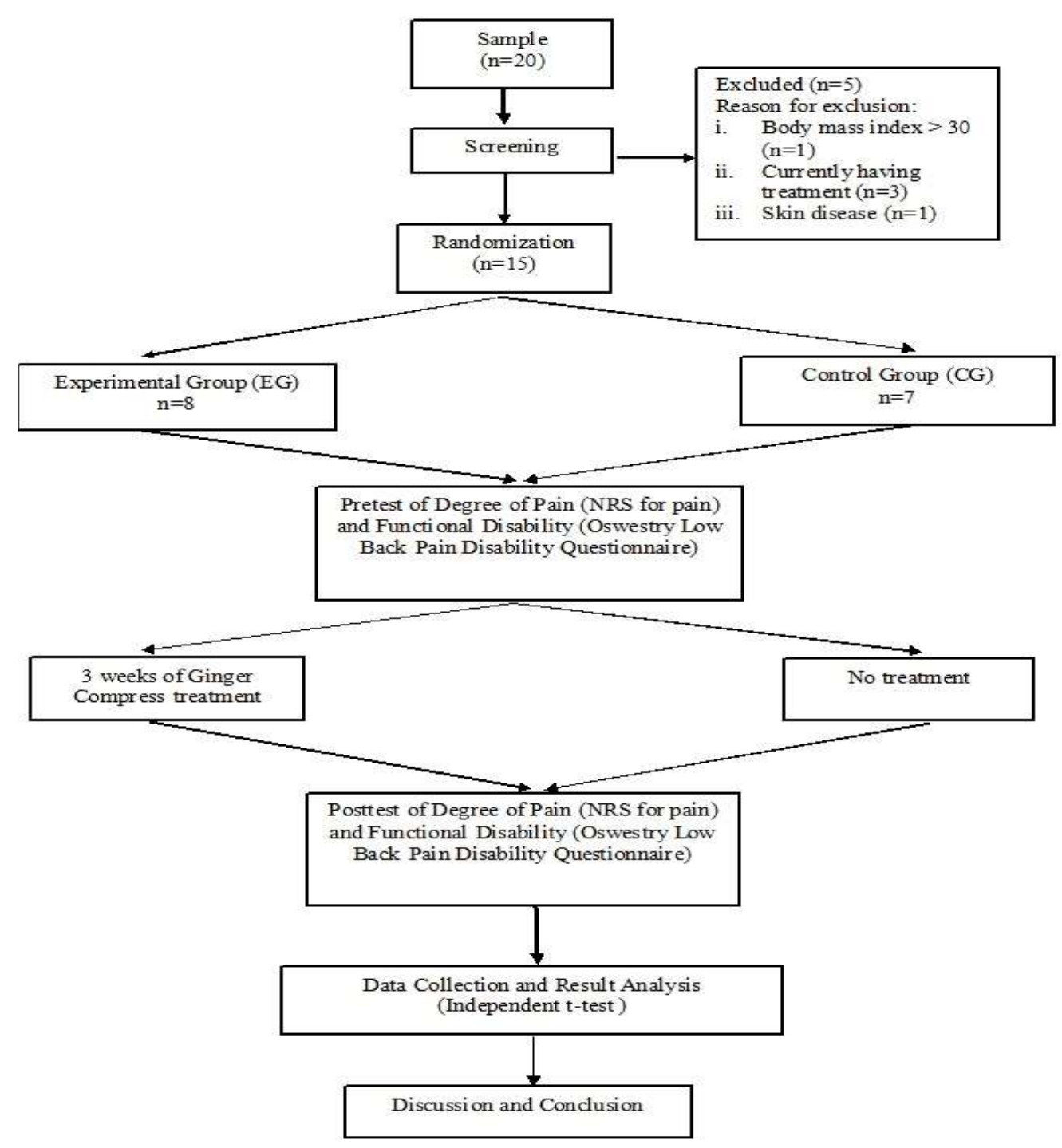

Fig.1. Research Procedure

\section{RESULTS}

The demographic data collected include age, gender, race, height, weight and duration of low back pain. The demographic data reported was divided into two different groups consist of the Experiment Group (EG) and Control Group (CG).There were 11 males (73.3\%) and 4 females (26.7\%). The participant age, height, weight, BMI and low back pain duration between experimental group and control group were similar, indicated that they were from homogeneous group. The descriptive characteristics for the 15 participants of the study were presented in Table1. 
Table 1. Demographic Data of Experimental Group and ControlGroup

\begin{tabular}{ccc}
\hline Variables & $\begin{array}{c}\text { Experimental Group }(\mathrm{n}=8) \\
(\mu \pm \mathrm{SD})\end{array}$ & $\begin{array}{c}\text { Control Group }(\mathrm{n}=7) \\
(\mu \pm \mathrm{SD})\end{array}$ \\
\hline Gender & 6 male $/ 2$ female & 5 male $/ 2$ female \\
Age (years) & $22.63 \pm 2.39$ & $22.43 \pm 0.98$ \\
Height (cm) & $168.63 \pm 8.86$ & $171 \pm 8.04$ \\
Weight $(\mathrm{kg})$ & $61.75 \pm 8.03$ & $67 \pm 12.68$ \\
BMI (kg $\left.\div \mathrm{cm}^{2}\right)$ & $21.66 \pm 1.74$ & $22.53 \pm 3.63$ \\
Low Back Pain Duration (months) & $18.50 \pm 17.74$ & $16 \pm 12.61$ \\
\hline
\end{tabular}

The comparison between experimental group and control group in non-specific low back pain relief after three weeks ginger compress intervention can be seen clearly through Figure 2.

\section{Degree of Pain}

7

6
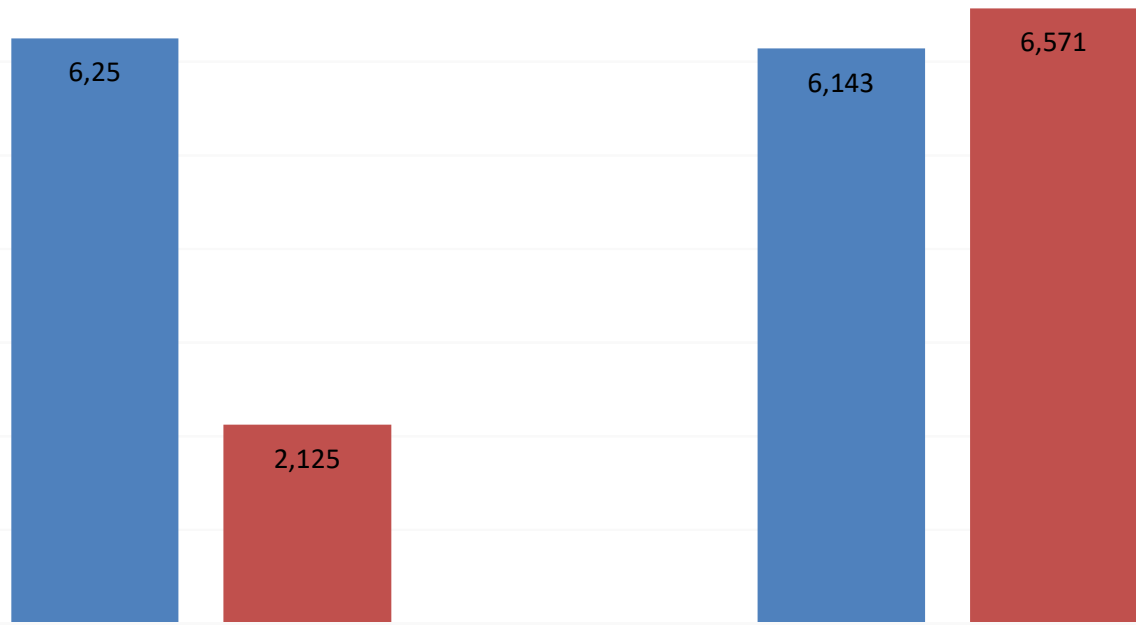

Experimental Group

Control Group

Pretest $\quad$ Posttest

Fig.2. The Mean Comparison between Experimental Group and Control Group in Non-Specific Low Back Pain Relief after Three Weeks Ginger Compress Intervention 
The pretest value between experimental group and control group in low back pain intensity showed that these two groups are in homogeneous group before three weeks ginger compress intervention $(\mathrm{t}=0.174, \mathrm{p}=0.864)$. After three weeks ginger compress intervention, there was a significant difference $(t=-8.730, p=0.000)$ between the experimental group and the control group (Refer Table2). In terms of pain relief within group, after three weeks ginger compress intervention, there was significant change in pain relief after three weeks ginger compress intervention ( $\mathrm{t}=7.201, \mathrm{p}=0.000)$ in experimental group while there was no significant change in control group $(\mathrm{t}=-0.783, \mathrm{p}=0.449)$.

Table 2. The Mean, Standard Deviation, $t$-value and p-value of Pretest and Posttest Between and Within Experimental Group and Control Group in Non-Specific Low BackPainRelief after Three Weeks Ginger Compress Intervention using Numeric Rating Scale

\begin{tabular}{ccccc}
\hline Group & $\begin{array}{c}\text { Pretest } \\
\mu \pm \mathrm{SD}\end{array}$ & $\begin{array}{c}\text { Posttest } \\
\mu \pm \mathrm{SD}\end{array}$ & $\mathrm{t}$ & $\mathrm{p}$ \\
\hline Experimental & $6.250 \pm 1.2817$ & $2.125 \pm .9910$ & 7.201 & $.000^{*}$ \\
Control & $6.143 \pm 1.0690$ & $6.571 \pm .9759$ & -.783 & .449 \\
\hline $\mathrm{t}$ & .174 & -8.730 & & \\
$\mathrm{p}$ & .864 & $.000^{*}$ & & \\
\hline
\end{tabular}

*Result is significant when $\mathrm{p}<0.05$.

The comparison between experimental group and control group in disability due to low back pain reduction after three weeks ginger compress intervention can be seen clearly through the Figure 3. 


\section{Disability Due to Low Back Pain}

25

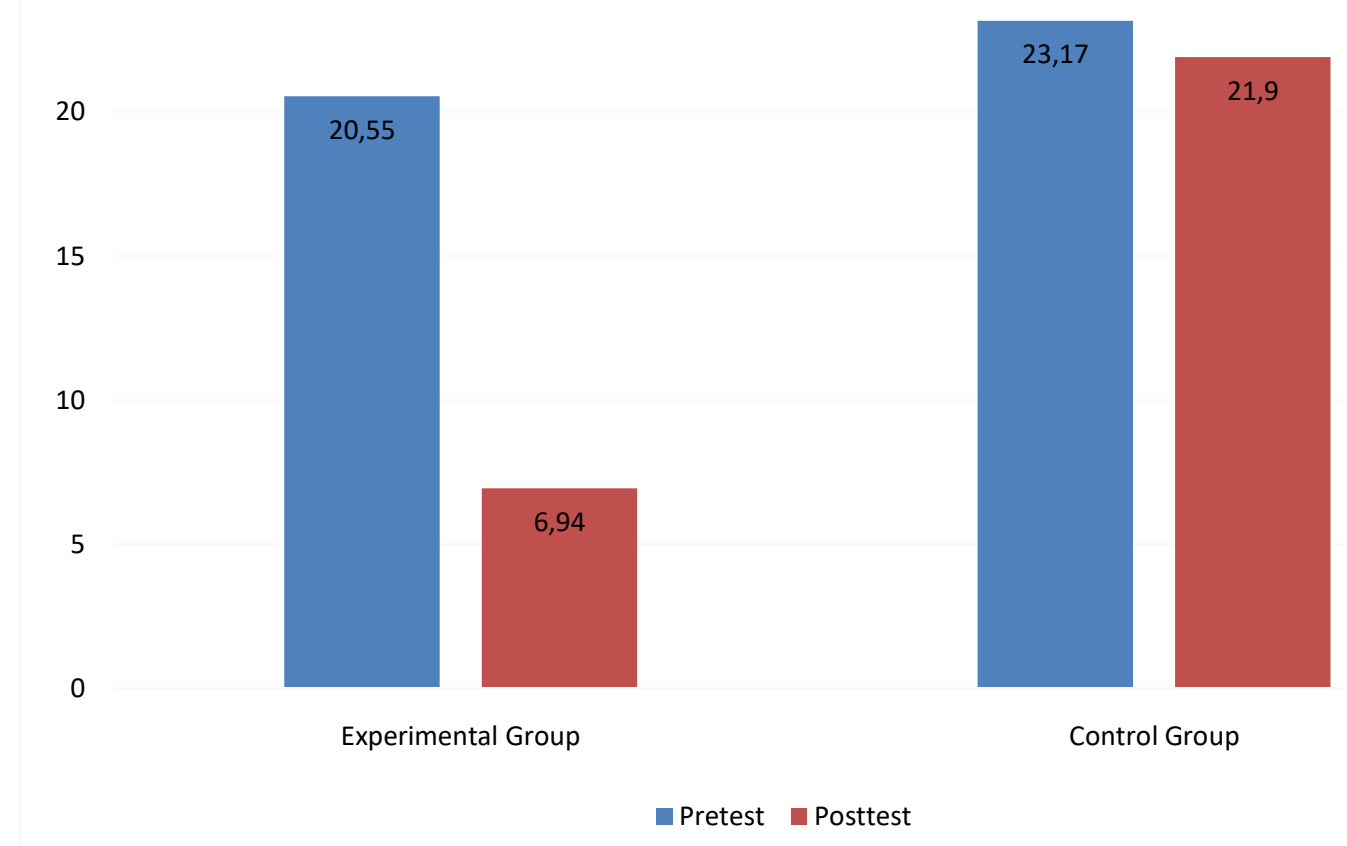

Fig.3. The Mean Comparison between Experimental Group and Control Group in Disability Reduced after Three Weeks Ginger Compress Intervention

The pretest value between experimental group and control group value in disability due to low back pain indicated that both groups were from homogeneous group before three weeks ginger compress intervention $(\mathrm{t}=-0.912, \mathrm{p}=0.379)$. After three weeks ginger compress intervention, there was significant difference $(\mathrm{t}=-5.786, \mathrm{p}=0.000)$ between experimental group and control group in disability value (Refer Table 3). In terms of disability reduced within group, there was significant change in disability reduction after three weeks ginger compress intervention $(\mathrm{t}=5.245, \mathrm{p}=0.000)$ in experimental group while there was no significant change in control group $(\mathrm{t}=0.441, \mathrm{p}=0.667)$. 
Table 3. The Mean, Standard Deviation, t-value and p-value of Pretest and Posttest Between and WithinExperimentalGroup and ControlGroup in Disability dueto Low Back PainReductionAfterThreeWeeksGingerCompressInterventionusing Oswetry

Disabilty Questionnaire

\begin{tabular}{ccccc}
\hline Group & $\begin{array}{c}\text { Pretest } \\
(\mu \pm \mathrm{SD})\end{array}$ & $\begin{array}{c}\text { Posttest } \\
(\mu \pm \mathrm{SD})\end{array}$ & $\mathrm{t}$ & $\mathrm{p}$ \\
\hline Experimental & $20.55 \pm 4.71$ & $6.94 \pm 5.63$ & 5.245 & $.000^{*}$ \\
Control & $23.17 \pm 6.40$ & $21.90 \pm 4.14$ & .441 & .667 \\
\hline $\mathrm{t}$ & -.912 & -5.786 & & \\
$\mathrm{p}$ & .379 & $.000^{*}$ & & \\
\hline
\end{tabular}

$*$ Result is significant when $\mathrm{p}<0.05$.

\section{DISCUSSION}

There was significant difference between experimental group and control group in non-specific low back pain relief $(\mathrm{t}=-8.730, \mathrm{p}=0.000)$ after three weeks ginger compress intervention. Ginger compress is effective in non-specific low back pain relief. This may due to ginger properties or thermo effect of ginger compress. Previous study reported patients having ginger compress to kidney experienced a harmonious warmth response, lasting relaxation, relief of symptoms, and increase of mobility [20].

Ginger compress is effective in non-specific low back pain relief as ginger has an analgesic and anti-inflammatory effect on musculoskeletal pain. Previous study reported the anti-inflammatory role of ginger constituents, which may reduce the subjective experience of pain in some conditions such as osteoarthritis [15]. This finding is supported by previous studies with the use of ginger in treating musculoskeletal pain, including knee pain $[21,22]$, muscle pain [23] and back pain [24] reported that ginger produced moderate to large reductions in pain $[21,23]$. A study showed that treatment with ginger was more effective than the placebo in mechanical pain due to osteoarthritis and can be a good alternative to 
non-steroidal anti-inflammatory drugs [25]. However, most of the previous studies used ginger as an extract taken orally and aromatic ginger oil combined with massage. One study using Swedish massage with ginger aromatic oil reported great reduction in back pain intensity [24].

Thomson [26] and his team suggested that the soothing action was related to dual inhibition of both the cyclooxygenase and lipooxygenase pathways (prostaglandin synthetase inhibition) in inflammatory processes by the active ingredients in ginger, gingerols and shogaol. The capsaicin-like effect of 6-shogaol is possibly the analgesic substance found in ginger that inhibits the release of the neuro-peptide, substance P [27]. The improvement noted in physical functioning may be related to a reduction in pain by these pharmacologic agents. Another study suggested that ginger can reduced the direct activation of type 3 and 4 afferent nerve fibers by substances such as bradykinin and sensitization of afferent fibers by prostaglandins and cytokines. As gingerols, shogaols, and zingerone are known as the transient receptor potential cation channel subfamily V member 1 (TRPV1) receptor agonists, located in dorsal root ganglion and central neural tissues, central involvement has also been implicated [28].

Some reviews recommended superficial heat application for pain relief $[17,18]$. Many episodes of low back pain result from a strain or over-exertion, creating tension in the muscles and soft tissues around the spine. The muscle spasm that results from the back injury can create sensations that range from mild discomfort to inability to move and excruciating pain. Heat therapy can help relieve both pain from the muscle spasm and related stiffness in the lower back $[29,30]$. Ginger compress may dilate the blood vessels of the muscles surrounding the lumbar spine. This process increases the flow of oxygen and nutrients to the muscles, helping to heal the damaged tissue while heat stimulates the sensory receptors in the skin, which means that applying heat to the lower back will decrease transmissions of pain signals to the brain and partially relieve the discomfort.

This study revealed there was significant difference between experimental group and control groups in disability reduction $(\mathrm{t}=-5.786, \mathrm{p}=0.000)$ after three weeks ginger compress intervention. Effectiveness of ginger compress in non-specific low back pain (LBP) relief 
further reduce disability due to LBP as pain affecting patients ability to manage their personal care, walking, lifting, sitting, standing, sleeping, travelling and social in everyday life. This is approved from the result indicated that the experimental group showed an average of $66 \%$ pain relief, directly proportional to an average of $66 \%$ disability reduced. This finding is supported by previous study reported that aromatic ginger oil improved significantly in disability level in knee pain [22] and chronic low back pain [24]. The study suggested that therapeutic benefit of aromatic ginger oil may be particularly beneficial for disability.

Superficial heat has been found to be helpful in diminishing pain and decreasing local muscle spasm. Previous study has shown increases of $3.8^{\circ} \mathrm{C}$ at $1 \mathrm{~cm}$ and $0.8^{\circ} \mathrm{C}$ at $3 \mathrm{~cm}$ deep in the triceps surae muscle during 20 minute silicate gel hot pack treatments [31]. With this increase in tissue temperature, moist heat increased tissue extensibility and range of motion of a joint and decreased muscle spasm [29]. Heatmay facilitate stretching soft tissues around the spine, including muscles, connective tissue, and adhesions. Consequently, with thermo effect of ginger compress, there will be a decrease in stiffness, with an increase in flexibility and hence reduced functional disability due to low back pain.

\section{CONCLUSION}

Low back pain is the most prevalent musculoskeletal condition and one of the most common causes of disability in developed and under developsnations. Hence, a treatment for low back pain which can help the patient to reduce pain as well as restoration of function is important.This study is conducted because there was limited research on ginger applied externally especially on the low back area. This study finding concludes that ginger compress is effective in relief non-specific low back pain and reduces functional disability due to low back pain. Hence, it may as a care option for health professional practice for patients with non-specific low back pain. Non-specific low back pain patient is suggested to use ginger compress as self-treatment methodbecause the preparation and application of ginger compress is easy, simple and least costly. 


\section{REFERENCES}

[1] Luo X, Pietrobon R, Sun SX, Liu GG, Hey L. Estimates and patterns of direct health care expenditures among individuals with back pain in the United States. Spine, 2004, 29(1), 79-86.

[2] Cherkin D C, Deyo R A, Volinn E, Loeser J D. Use of the International Classification of Diseases (ICD-9-CM) to identify hospitalizations for mechanical low back problems in administrative databases. Spine, 1992, 17(7), 817-825.

[3] EhrlichGE.Low back pain. Bulletin of the World Health Organization, 2003, 81(9),691-693.

[4] Deyo R A, Phillips W R. Low back pain: a primary care challenge. Spine, 1996, 21(24), 2826-2832.

[5] Natour J, Cazotti L D, Ribeiro L H, Baptista A S, Jones A. Pilates improves pain, function and quality of life in patients with chronic low back pain: a randomized controlled trial. Clinical rehabilitation, 2015, 29(1), 59-68.

[6] Croft P, Rigby A S, Boswell R, Schollum J, Silman A. The prevalence of chronic widespread pain in the general population.The Journal of rheumatology, 1993, 20(4), 710-713.

[7] Nguyen T H, Randolph D C. Nonspecific low back pain and return to work. American family physician, 2007, 76(10).

[8] Altman R D, Marcussen K C. Effects of a ginger extract on knee pain in patients with osteoarthritis. Arthritis \& Rheumatology, 2001, 44(11), 2531-2538.

[9] Geiger J L. The essential oil of ginger, Zingiberofficinale, and anaesthesia. International Journal of Aromatherapy, 2005, 15(1), 7-14.

[10] Terry R, Posadzki P, Watson L K, Ernst E. The use of ginger (Zingiberofficinale) for the treatment of pain: a systematic review of clinical trials. Pain medicine, 2011, 12(12), 1808-1818.

[11] Xu X, Jiang Z, Du X, editors. Complete external therapies of Chinese drugs. Foreign Languages Press, 1998.

[12] Fingado M. TherapeutischeWickel und Kompressen: Handbuchaus der 
Ita-WegmannKlinik. Natura-Verlag, 2001.

[13] Leach M J, Kumar S. The clinical effectiveness of Ginger (Zingiberofficinale) in adults with osteoarthritis. International Journal of Evidence-Based Healthcare, 2008, 6(3), 311-320.

[14] Pour H A, Norouzzade R, Heidari M R, Ogut S, Yaman H, Gokce S. Therapeutic Properties of Zingiberofficinale Roscoe: A Review. 2014.

[15] Terry R, Posadzki P, Watson L K, Ernst E. The use of ginger (Zingiberofficinale) for the treatment of pain: a systematic review of clinical trials. Pain medicine, 2011, 12(12), 1808-1818.

[16] Long B C, Hopkins J T. Superficial moist heat's lack of influence on soleus function. Journal of sport rehabilitation, 2009, 18(3), 438-447.

[17] Hawkes A R, Draper D O, Johnson A W, Diede M T, Rigby J H. Heating capacity of ReBound shortwave diathermy and moist hot packs at superficial depths. Journal of athletic training, 2013, 48(4), 471-476.

[18] Lin Y H. Effects of thermal therapy in improving the passive range of knee motion: comparison of cold and superficial heat applications. Clinical rehabilitation, 2003, 17(6), 618-623.

[19] French S D, Cameron M, Walker B F, Reggars J W, Esterman A J. A Cochrane review of superficial heat or cold for low back pain.Spine.2006, 31(9), 998-1006.

[20] Therkleson T, Sherwood P. Patients' experience of the external therapeutic application of ginger by anthroposophically trained nurses. Indo-Pacific Journal of Phenomenology, 2004, $4(1)$.

[21] Altman R D, Marcussen K C. Effects of a ginger extract on knee pain in patients with osteoarthritis. Arthritis \& Rheumatology, 2001, 44(11), 2531-2538.

[22] Yip Y B, Tam A C. An experimental study on the effectiveness of massage with aromatic ginger and orange essential oil for moderate-to-severe knee pain among the elderly in Hong Kong.Complementary therapies in medicine, 2008, 16(3), 131-138.

[23] Black, C. D., Herring, M. P., Hurley, D. J., \& O'Connor, P. J. (2010). Ginger (Zingiberofficinale) reduces muscle pain caused by eccentric exercise. The Journal of Pain, 11(9), 894-903. 
[24] Sritoomma N, Moyle W, Cooke M, O’ Dwyer S. The effectiveness of Swedish massage with aromatic ginger oil in treating chronic low back pain in older adults: a randomized controlled trial. Complementary therapies in medicine, 2014, 22(1), 26-33.

[25] Khalvat A. Comparing the effects of ginger (Zingiberofficinale) extract and ibuprofen on patients with osteoarthritis.Archives of Iranian medicine, 2005, 8(4), 267-271.

[26] Thomson M, Al-Qattan K K, Al-Sawan S M, Alnaqeeb M A, Khan I, Ali M. The use of ginger (ZingiberofficinaleRosc.) as a potential anti-inflammatory and antithrombotic agent.Prostaglandins, leukotrienes and essential fatty acids, 2002, 67(6), 475-8.

[27] Geiger J L. The essential oil of ginger, Zingiberofficinale, and anaesthesia. International Journal of Aromatherapy, 2005, 15(1), 7-14.

[28] Chrubasik S, Pittler M H, Roufogalis B D. Zingiberisrhizoma: a comprehensive review on the ginger effect and efficacy profiles. Phytomedicine, 2005, 12(9), 684-701.

[29] Knight C A, Rutledge C R, Cox M E, Acosta M, Hall S J. Effect of superficial heat, deep heat, and active exercise warm-up on the extensibility of the plantar flexors. Physical Therapy, 2001, 81(6), 1206-1214.

[30] Bell G W, Prentice W E. Infrared modalities (therapeutic heat and cold). Therapeutic Modalities in Sports Medicine.(4th Ed), Boston: WCB McGraw-Hill, 1999, pp. 173-206.

[31] Draper D O, Harris S T, Schulthies S, Durrant E, Knight K L, Ricard M. Hot-pack and 1-MHz ultrasound treatments have an additive effect on muscle temperature increase. Journal of athletic training, 1998, 33(1), 21.

\section{How to cite this article:}

Lem H. W. And Lee A. C. The effectiveness of Ginger Compresson Non-Specific Low Back Pain. J. Fundam. Appl. Sci., 2017, 9(6S), 1173-1186. 